\title{
Numerical Study on the Effects of Imbibition on Gas Production and Shut-In Time Optimization in Woodford Shale Formation
}

\author{
Zhou Zhou ${ }^{1, *}$, Shiming Wei ${ }^{1}$, Rong $\mathrm{Lu}^{2}$ and Xiaopeng $\mathrm{Li}^{3}$ \\ 1 State Key Laboratory of Petroleum Resources and Prospecting, China University of Petroleum (Beijing), \\ Beijing 1002249, China; we_shiming@163.com \\ 2 Petroleum Engineering Department, Colorado School of Mines, Golden, CO 80401, USA; rlu@mines.edu \\ 3 FracGeo LLC, Aurora, CO 80015, USA; roy.li.inbox@gmail.com \\ * Correspondence: zhouzhou@cup.edu.cn; Tel.: +86-10-8973-2165
}

Received: 23 May 2020; Accepted: 17 June 2020; Published: 21 June 2020

\begin{abstract}
In shale gas formations, imbibition is significant since the tight pore structure causes a strong capillary suction pressure. After hydraulic fracturing, imbibition during the period of shut-in affects the water recovery of flowback. Although there have been many studies investigating imbibition in shale formations, few papers have studied the relationship between gas production and shut-in time under the influence of imbibition. This paper developed a numerical model to investigate the effect of imbibition on gas production to optimize the shut-in time after hydraulic fracturing. This numerical model is a 2-D two-phase (gas and water) imbibition model for simulating an imbibed fluid flow and its effect on permeability, flowback, and water recovery. The experimental and field data from the Woodford shale formation were matched by the model to properly configure and calibrate the model parameters. The experimental data consisted of the relationship between the imbibed fluid volume and permeability change, the relative permeability, and the capillary pressure for the Woodford shale samples. The Woodford field data included the gas production and flowback volume. The modeling results indicate that imbibition can be a beneficial factor for gas production, since it can increase rock permeability. However, the gas production would be reduced when excessive fluid is imbibed by the shale matrix. Therefore, the shut-in time after hydraulic fracturing, when the imbibition happens in shale, could be optimized to maximize the gas production.
\end{abstract}

Keywords: imbibition; gas production; hydraulic fracturing; shut-in time; shale gas formation

\section{Introduction}

Hydraulic fracturing is a method to improve gas production in shale formations. Well shut-in is one of the necessary steps during the hydraulic fracturing operation to calm down the formation and prepare the flow back. According to field data, the shut-in time is related to the production of shale gas formations. Almulhim et al. found that the gas production peak and cumulative gas production could be higher when the shut-in time was longer in some shale gas formations, which had strong water-wet characteristics [1]. Bertoncello et al. also indicated that up to two months of shut-in could bring a better performance in the cumulative production of the shale gas formation compared with the most current shut-in times, which were very short in the field [2]. The long shut-in time leads to a small water recovery. The common opinion is that as much water recovery as possible is important to prevent formation damage. However, based on the field reports in shale formations from Alkouh and Wattenbarger, less than $50 \%$ of the injection fluid was recovered when the shut-in took longer to achieve a better production [3]. 
The reason for the small water recovery in shale gas formations is that a longer shut-in time can result in fluid flow from fracture faces to deep inside the rock matrix [4]. This fluid flow is called imbibition. Imbibition is defined as a flow of immiscible fluids in a porous rock. It can cause a larger stimulation reservoir volume in shale formations with complex natural fractures so that the percentage of fracture fluid recovery is small and takes a much longer time to complete flow back [5]. During flowing, most of the remaining fluid is imbibed by the rock matrix. Hence, imbibition during the shut-in is considered to result in a small amount of water recovery [1,6-8].

Roychaudhuri et al., Makhanov et al., and Zhou et al., have proved that a large volume of the fracturing fluid can be imbibed by the shale samples [9-12]. However, few studies have investigated the relationship between imbibition, shut-in time, water recovery, and gas production. Therefore, this paper developed a numerical model to simulate an imbibed fluid flow and its effect on permeability, production, and water recovery. Additionally, the model could be applied to optimize the shut-in time based on this relationship to achieve the best gas production performance. The highlight of this study is to quantitatively combine the imbibition with the gas-water flow model.

In this paper, the experimental and field data of the Woodford shale formation were considered by the model to study the effect of imbibition on gas production and shut-in time optimization. The data included the imbibition volume, rock permeability change, relative permeability, capillary pressure, daily flowback rate and volume, and gas production, which were matched by the model to achieve the parameters for simulating. The contribution of this model is to understand the relationship of the imbibition to the gas production in shale formations and close the gap between experimental research and field operations.

\section{Formation Characterization}

The field data used in this study are from the Cana Field of western Oklahoma. The field is located in the Anadarko Basin with the initial development program started in Canadian County, as shown in the map of Figure 1.

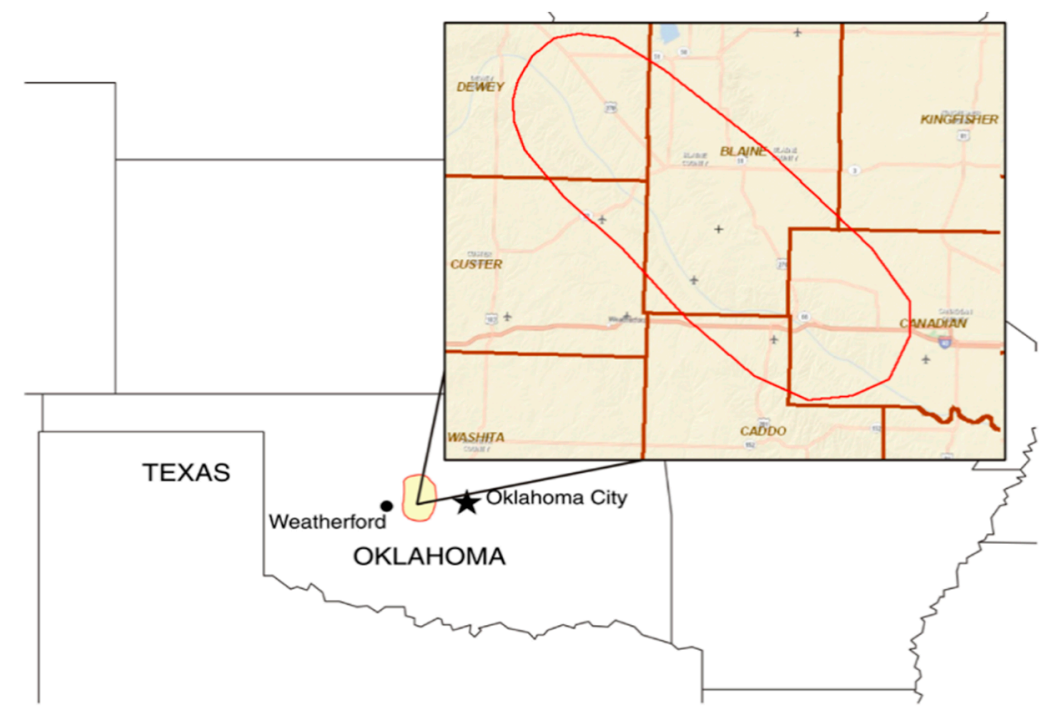

Figure 1. Location map of the Woodford shale formation [13].

Cana Field produces from the Upper Devonian Woodford Shale, and the production is mainly composed of gas, condensate, and natural gas liquids. The stratigraphic chart of the target formation is shown in Table 1. 
Table 1. Stratigraphic chart [14].

\begin{tabular}{|c|c|c|}
\hline \multicolumn{2}{|c|}{ AGE } & \multirow{2}{*}{$\begin{array}{c}\text { STRATIGRAPHIC UNIT } \\
\text { Cana Field }\end{array}$} \\
\hline SYSTEM & SERIES & \\
\hline \multirow{3}{*}{ PENNSYLVANIAN } & DESMOINES & $\begin{array}{l}\text { Boggy Formation } \\
\text { Hartshorn Sandstone }\end{array}$ \\
\hline & ATOKA & $\begin{array}{l}\text { Atoka Formation } \\
\text { Spiro Sandstone }\end{array}$ \\
\hline & MORROW & $\begin{array}{l}\text { Wapanucka Limestone } \\
\text { Game Refuge Sandstone }\end{array}$ \\
\hline \multicolumn{2}{|c|}{ MISSISSIPPIAN } & $\begin{array}{l}\text { Springer Group } \\
\text { Caney Shale }\end{array}$ \\
\hline \multicolumn{2}{|c|}{ DEVONIAN } & Woodford Shale \\
\hline \multicolumn{2}{|c|}{ SILURIAN } & Hunton Group \\
\hline \multicolumn{2}{|c|}{ ORDOVICIAN } & \\
\hline \multicolumn{2}{|c|}{ CAMBRIAN } & $\begin{array}{c}\text { Sylvan Shale } \\
\text { Viola Limestone } \\
\text { Simpson Group } \\
\text { Arbuckle Group }\end{array}$ \\
\hline \multicolumn{2}{|c|}{ PRECAMBRIAN } & $\begin{array}{l}\text { Honey Creek Dolomite } \\
\text { Reagan Sandstone }\end{array}$ \\
\hline
\end{tabular}

XRD testing is summarized in Table 2 for the Woodford shale samples. It indicates that the major mineral is quartz and the second is illite. Hence, the formation is clay-rich.

Table 2. Mineral content of the samples of Woodford shale (weight $\%$ ).

\begin{tabular}{ccccccccccc}
\hline ID & Quartz & K-Feldspar & Plagioclase & Calcite & Dolomite & Mg-Siderite & Pyrite & Marcasite & I/S & Illite \& Mica \\
\hline 1 & 42.4 & 6.4 & 10.5 & 0.6 & 7.8 & 1.4 & 8.1 & 3.7 & 0 & 19.3 \\
2 & 60.1 & 5 & 6.6 & 0.5 & 8.1 & 0 & 2.6 & 0.6 & 0 & 16.5 \\
3 & 38.7 & 7.1 & 4.9 & 0.9 & 9.5 & 2.8 & 2.1 & 0 & 5.8 & 28.2 \\
4 & 42.8 & 5.9 & 7.8 & 0.6 & 18.3 & 1.1 & 4.3 & 1.6 & 0 & 17.6 \\
\hline
\end{tabular}

Other geological and rock properties are shown in Table 3.

Table 3. Geological and rock properties of the Woodford shale samples.

\begin{tabular}{ccccc}
\hline $\begin{array}{c}\text { TOC } \\
\mathbf{( \% )}\end{array}$ & $\begin{array}{c}\text { Grain Density } \\
(\mathbf{g m} / \mathbf{c c})\end{array}$ & $\begin{array}{c}\text { Initial Water Saturation } \\
\mathbf{( \%} \text { of } \mathbf{P V})\end{array}$ & $\begin{array}{c}\text { Porosity } \\
\mathbf{( \% ) ~ o f ~ B V ) ~}\end{array}$ & $\begin{array}{c}\text { Permeability } \\
(\mathbf{m d})\end{array}$ \\
\hline 7.81 & 2.497 & 14.992 & 5.33 & $3.31 \times 10^{-5}$ \\
8.18 & 2.487 & 16.905 & 4.01 & $1.16 \times 10^{-5}$ \\
8.16 & 2.434 & 17.671 & 4.86 & $6.69 \times 10^{-5}$ \\
7.56 & 2.480 & 27.489 & 3.77 & $1.18 \times 10^{-5}$ \\
\hline
\end{tabular}

\section{Numerical Model}

In this paper, we introduce a numerical model which considers imbibition to simulate the fluid flow from porous media into hydraulic fractures. The experimental and field data from the Woodford Shale formation are collected [15-17]. The data are used to show the relationship between imbibition, permeability, capillary pressure, and complex transport mechanisms. There are two main assumptions for the model when studying the shut-in time. One is that the length of the hydraulic fracture is assumed constant after shut-in. Although some further fracture propagation can still take place, there is not a sufficient amount of proppants to support those lengths to make a significant contribution to the flow. Another assumption is that the fluid pressure in hydraulic fractures keeps constant. This assumption is because the permeability in shale formation is too small, so it is difficult to impact the pressure in fractures by formation. In addition, it neglects some effects from the proppant and gel filter cake on the fracture conductivity during the shut-in period. 


\subsection{Fundamental Equations}

The mass conservation equations for gas and fracturing fluids in porous media are:

$$
\begin{gathered}
\frac{\partial\left(\phi \rho_{w} s_{w}\right)}{\partial t}=\nabla \cdot\left(\rho_{w} \frac{K k_{r w}}{\mu_{w}} \nabla p_{w}\right), \\
\frac{\partial\left(\phi \rho_{g} s_{g}\right)}{\partial t}=\nabla \cdot\left(\rho_{g} \frac{\widetilde{K k} k_{r g}}{\mu_{g}} \nabla p_{g}\right), \\
s_{g}=1-s_{w}, \\
p_{g}=p_{w}+p_{c}\left(s_{w}\right),
\end{gathered}
$$

where $\phi$ is the rock porosity. $\rho_{w}$ and $\rho_{g}$ are, respectively, the water density and gas density. $s_{w}$ and $s_{g}$ are, respectively, the water and gas saturation. $K$ is the absolute permeability. $k_{r w}$ and $k_{r g}$ are, respectively, the phase permeability of water and gas. $\widetilde{k}$ is the apparent permeability of gas, which is the enhanced gas mobility considering different transport mechanisms [18]. The water phase is assumed to follow Darcy's law, thus its apparent permeability is $1 . \mu_{w}$ and $\mu_{g}$ are, respectively, the water and gas viscosity. $p_{w}$ and $p_{g}$ are, respectively, the water and gas pressure. $p_{c}$ is the capillary pressure, which is the function of water saturation, and the specific function of capillary pressure can be obtained through mercury injection experiments. The detailed solving procedure is included in the Appendix A.

The equation of state for the real gas can be expressed as:

$$
p=\text { ZRTC }, \quad \rho_{g}=C M,
$$

where $R$ is the universal gas constant. $T$ is the formation temperature. $C$ is the gas concentration. $Z$ is the ratio of gas volume in the real condition to the gas volume in the ideal condition, and it can be expressed as $[19,20]$ :

$$
\begin{aligned}
Z= & 1+\left(A_{1}+\frac{A_{2}}{T_{r}}+\frac{A_{3}}{T_{r}^{3}}+\frac{A_{4}}{T_{r}^{4}}+\frac{A_{5}}{T_{r}^{5}}\right) \rho_{r}+\left(A_{6}+\frac{A_{7}}{T_{r}}+\frac{A_{8}}{T_{r}^{2}}\right) \rho_{r}^{2} \\
& -A_{9}\left(\frac{A_{7}}{T_{r}}+\frac{A_{8}}{T_{r}^{2}}\right) \rho_{r}^{5}+A_{10}\left(1+A_{11} \rho_{r}^{2}\right)\left(\rho_{r}^{2} / T_{r}^{3}\right) e^{\left(-A_{11} \rho_{r}^{2}\right)}
\end{aligned}
$$

The reduced density can be defined as:

$$
\rho_{r}=\frac{0.27 T_{c r}}{p_{c r} T} p,
$$

where $T_{c r}$ and $p_{c r}$ are, respectively, the critical temperature and critical pressure, and $T_{r}=T / T_{c r}$ stands for the reduced temperature. The eleven coefficients of Equation (6) are given below [20]:

$$
\begin{array}{lll}
A_{1}=0.3265 & A_{2}=-1.0700 & A_{3}=-0.5339 \\
A_{4}=0.01569 & A_{5}=-0.05165 & A_{6}=0.5475 \\
A_{7}=-0.7361 & A_{8}=0.1844 & A_{9}=0.1056 \\
A_{10}=0.6134 & A_{11}=0.7210 &
\end{array}
$$

\subsection{Imbibition Effect during the Shut-In Period}

During the shut-in period, the fracturing fluid has two aspects of influence on the shale matrix. Its first is to flow into the matrix to reduce the relative gas permeability. Second is that the imbibed fracturing fluid induces micro-fractures in the shale matrix to increase the absolute permeability of shale reservoirs. Those two influences were proved in the experiment [17]. The model in this paper can combine the influences to optimize the shut-in time in shale gas formations. 


\subsubsection{Relative Permeability}

The gas-water relative permeability and capillary curves are essential to the calculation of the gas-water flow in porous mediums. The experimental data of gas-water relative permeability and capillary pressure can usually be fitted with the power functions given below [21].

$$
\begin{gathered}
k_{r w}=s_{e}^{\frac{2+3 \lambda}{\lambda}}, \quad k_{r g}=\left(1-s_{e}\right)^{2}\left(1-s_{e}^{\frac{2+\lambda}{\lambda}}\right), \\
p_{c}=p_{d} s_{e}^{-1 / \lambda,}
\end{gathered}
$$

where $s_{e}$ is the effective water saturation, and $s_{e}=\left(s_{w}-s_{w r}\right) /\left(1-s_{w r}-s_{o r}\right) . \lambda$ is related to the pore size distribution [22].

The original data of the relative permeability curves and capillary curves are shown in Figures 2 and 3. They were originally from the experimental results from Charoenwongsa $(2011,2013)$ and $\mathrm{Lu}$ (2014) $[15,16,23]$. The shale cores in the imbibition experiment and relative permeability experiment were also from the Woodford Shale formation. Due to the fact that the Brooks-Corey relation originated from the experimental data of sand cores, these data from shale cores cannot be well fitted by Equations (9) and (10). The specific power functions used to fit these data are given in Equations (11)-(13), and the value of the determination coefficients of Equations (11)-(13) are all above 0.98, which shows the perfect agreement between these fitting equations and the experimental data [24].

$$
\begin{gathered}
k_{r w}=0.0784 s_{e}{ }^{2}-0.0019 s_{e}+0.0014 \\
k_{r g}=-0.2129 s_{e}{ }^{3}+0.5871 s_{e}{ }^{2}-0.5428 s_{e}+0.1711 \\
p_{c}=-29.281 s_{e}{ }^{5}+112.39 s_{e}{ }^{4}-174.97 s_{e}{ }^{3}+138.63 s_{e}{ }^{2}-56.075 s_{e}+9.3115[\mathrm{MPa}] .
\end{gathered}
$$

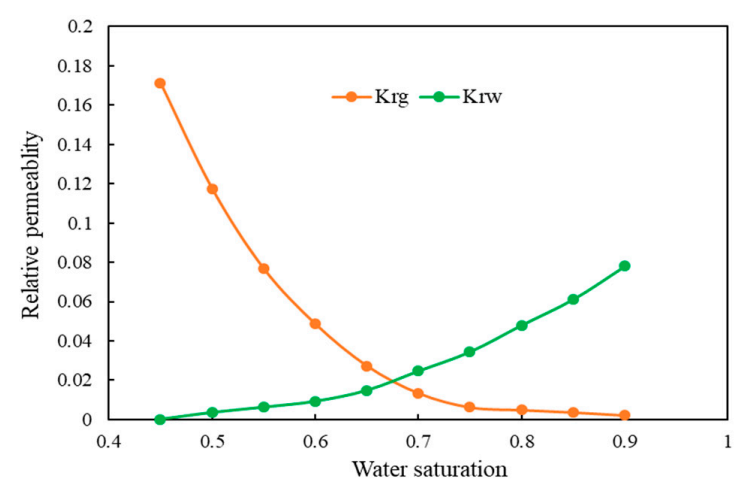

Figure 2. The gas-water relative permeability curve of the Woodford shale.

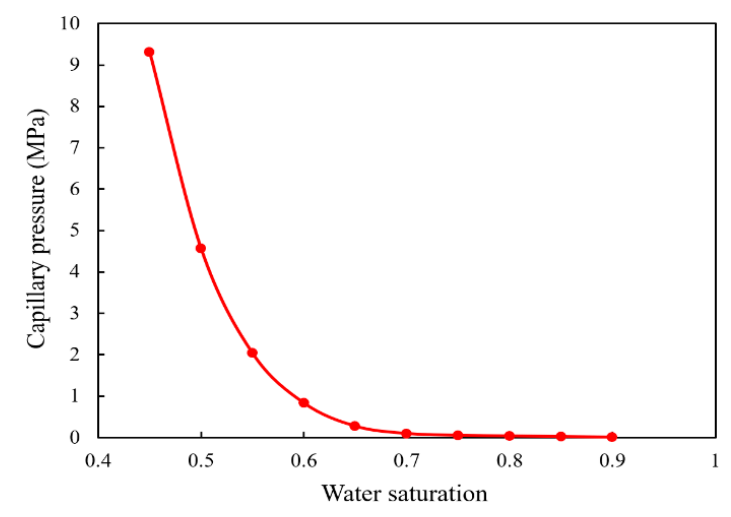

Figure 3. The capillary curve of the Woodford shale. 


\subsubsection{Imbibition Effect}

The traditional opinion is that the shut-in time during hydraulic fracturing should be as short as possible to prevent permeability decline due to water blockage. In shale formations, the imbibed fluids can induce microfractures, which improve the absolute matrix permeability. According to the experiment, the shale permeability can increase by 2 orders of magnitude in the imbibition experiments [17]. The overall permeability is proposed to describe the absolute permeability of the wet shale sample. The pressure build-up method was used for the wet shale sample permeability measurement. This is one of the most efficient methods to measure the permeability of tight rocks [12,17].

This paper considers the effect of imbibition on permeability based on Zhou's experiments (2016). The experimental data of the imbibed water saturation and overall permeability are given in Figure 4, and the data are from Zhou et al. [17]. Enhanced permeability is the permeability ratio of wet shale samples to dry shale samples. Figure 4 indicates that the overall permeability of the shale sample increases when the imbibition starts. When the imbibition saturation reaches 0.45 , the enhanced permeability of the shale sample reaches up to 36.2. The imbibition experimental data can be well fitted with the exponential function:

$$
K / K_{d r y}=0.8988 e^{8.2155 s_{w}}
$$

where $K_{d r y}$ is the permeability of the dry shale samples. $K$ is the permeability of the wet shale samples. Because Equation (14) is obtained by fitting the experimental data and is optimized with minimum error, $K$ is not equal to $K_{d r y}$ when the water saturation is 0 , which contradicts the physical meaning of the value. However, when the initial water saturation of the shale gas reservoir is 0.46 , and the irreducible water saturation is 0.45 , the unphysical value of $K / K_{d r y}$ will not appear.

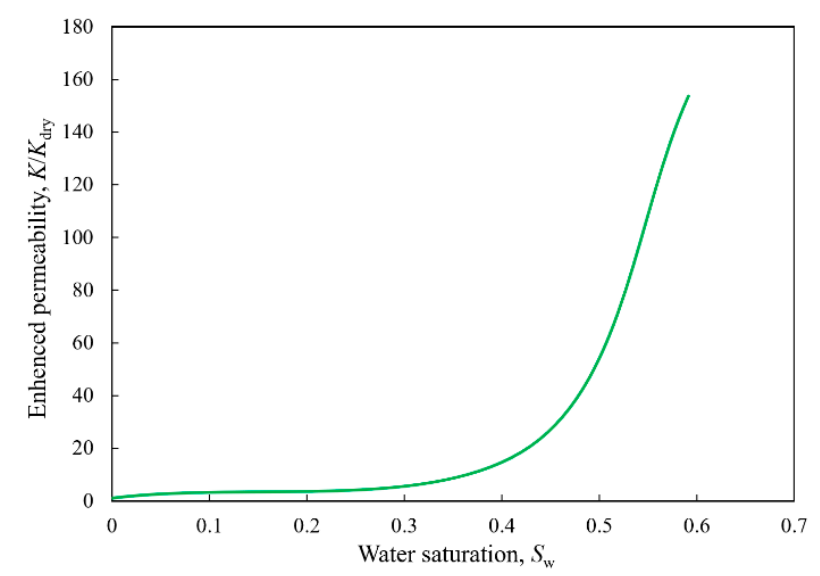

Figure 4. The experimental data obtained from Zhou et al. [17]. $K_{d r y}$ is the permeability of the dry shale core.

\subsubsection{Shut-In Time}

Shut-in time influences the imbibition region, as shown in Figure 5. When the shut-in time is short, the imbibition region is small, so that in matrix gas relative permeability is not affected by water invasion. At the same time, based on the experiment, the imbibition would induce microfractures to increase the permeability of the formation (see Figure 5a). When the shut-in time is longer, the imbibition region is bigger in the formation to reduce the gas relative permeability in the rock matrix (see Figure 5b). Meanwhile, the induced microfractures would not change too much. Hence, that is the reason that it is necessary to optimize the shut-in time. Figure 6 shows the relationship between the enhanced gas permeability (i.e., $k \cdot k_{r g} / k_{0}$ ) and water saturation in the shale matrix, and the enhanced gas permeability is 1 in the initial water saturation. It can be seen from Figure 6 that when we consider the influence 
of imbibition, the higher the water saturation, the larger the gas permeability. The enhanced gas permeability goes up sharply when the water saturation is over 0.8 .

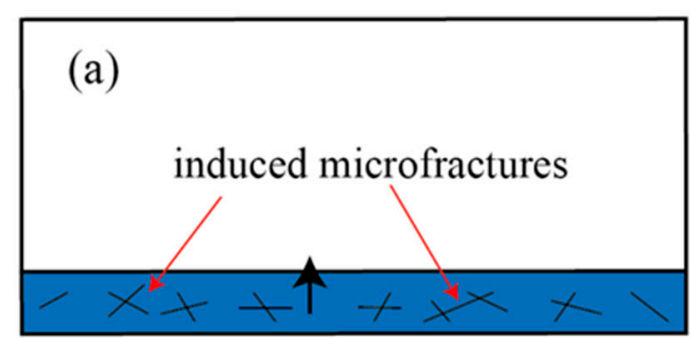

fracture surface (b)

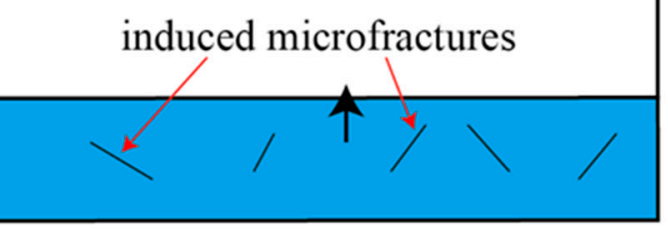

fracture surface

Figure 5. The influence of the shut-in time: (a) shut-in time is shorter; (b) shut-in time is longer.

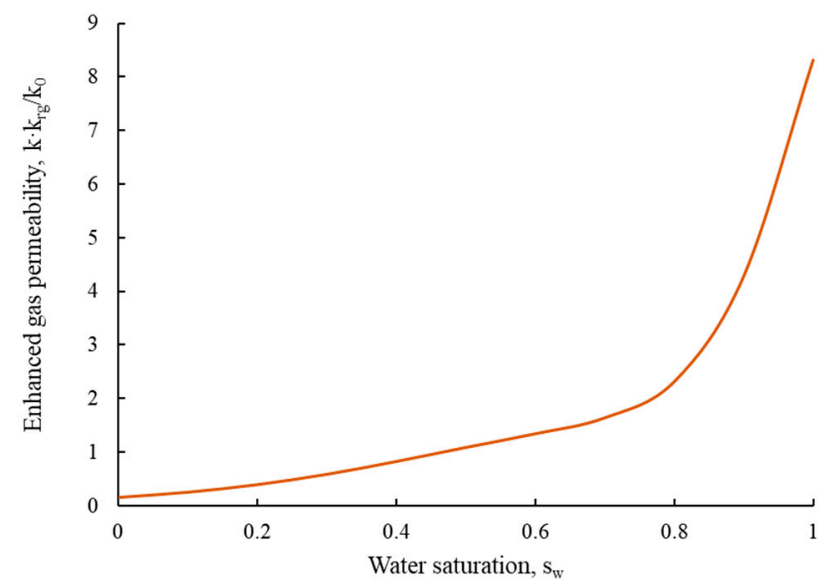

Figure 6. The relation between enhanced gas permeability and water saturation in the shale matrix.

During the shut-in time, micro fractures do not occur until the shale matrix has been in contact with the fluids for some time, over 1 day in Zhou's experiments (2016a). Therefore, the enhanced gas permeability is given at the end of the shut-in time. Once the microfractures appear, the matrix permeability will not decrease with the decline of water saturation. Thus, the process of permeability enhancement is not reversible in the production process. As shown in Figures 5 and 6, coupling the imbibition effect with the gas-water flow model optimizes the shut-in time in shale gas reservoirs.

\subsection{Complex Transport Mechanisms}

Due to the co-existence of nano-pores and micro-fractures in shale, the shale gas flow is controlled by different transport mechanisms. Based on the ratio of the molecular-free path to the pore characteristic length, the Knudsen number is defined to determine the flow mechanism in pores of different scales [25]. The range of Knudsen numbers and the corresponding flow mechanisms are shown in Figure 7.

$$
K_{n}=\frac{\lambda}{r}
$$

where $\lambda$ and $r$ are respectively the mean-free path of molecules and the pore characteristic length. Figure 7 gives the range of Knudsen numbers and the corresponding flow mechanisms. 


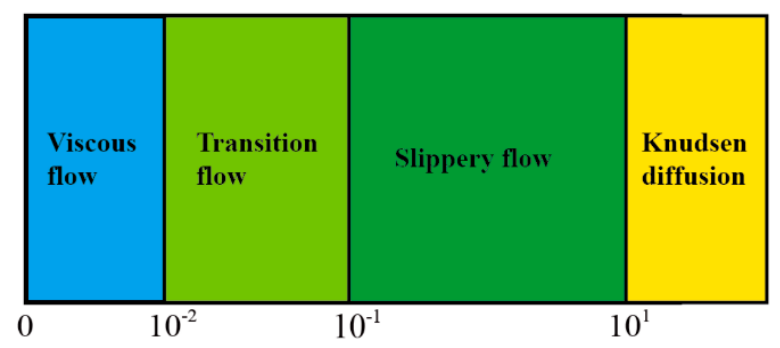

Figure 7. The range of Knudsen numbers and the corresponding flow mechanisms.

Based on Cao et al. (2016), the Knudsen number and apparent permeability of shale are formulated as [26]:

$$
\begin{gathered}
K_{n}=\frac{K_{B} T}{\sqrt{2} \pi \lambda_{c}^{2} p_{g}} \frac{\sqrt{\phi}}{2 \sqrt{2 k \tau}}, \\
\widetilde{k}=\left(1+\zeta K_{n}\right)\left(1+\frac{4 K_{n}}{1+K_{n}}\right),
\end{gathered}
$$

where $K_{B}$ is the Boltzmann constant. $\lambda_{c}$ is the collision diameter of gas molecules. $\zeta$ is the dimensionless rarefaction coefficient of gas, which is also the function of the Knudsen number [26]:

$$
\zeta=\frac{\zeta_{0}}{1+\frac{A}{\left(K_{n}\right)^{B}}},
$$

where $A, B$, and $\zeta_{0}$ are constants. In this paper, $A=0.17, B=0.4348$ [26].

The influence of imbibition, capillary pressure, and complex transport mechanisms on shale gas flow are considered through Equations (12), (14) and (17).

\section{Field Data Matching}

The gas production and flowback rate of the Woodford shale formation are used for history data matching. The field data and initial input parameters of the model are from Lu [16]. The input parameters are summarized in Table 4. The simulation setup is shown in Figure 8. The history data matching results for the well are shown in Figures 9 and 10.

Table 4. The basic input parameters for the well in the Cana Woodford Shale formation.

\begin{tabular}{cccc}
\hline Input Parameters & Values & Input Parameters & Values \\
\hline Injection rate & $0.2459 \mathrm{~m}^{3} / \mathrm{s}$ & Reservoir depth & $3930.1 \mathrm{~m}$ \\
Injection volume per cluster & $767.864 \mathrm{~m}^{3}$ & Reservoir porosity & 0.095 \\
shut-in time & 1 day & Reservoir permeability & $6.5 \times 10^{-20} \mathrm{~m}^{2}$ \\
Formation pressure gradient & $1.221 \times 10^{4} \mathrm{~Pa} / \mathrm{m}$ & Reservoir pay thickness & $45.72 \mathrm{~m}$ \\
\hline Bottom hole pressure & $2.413 \times 10^{7} \mathrm{~Pa}$ & Half fracture length & $99.97 \mathrm{~m}$ \\
Irreducible water saturation & 0.45 & Irreducible gas saturation & 0.1 \\
Gas critical temperature & $190.7 \mathrm{~K}$ & Gas critical pressure & $4.539 \times 10^{6} \mathrm{~Pa}$ \\
Gas viscosity & $1 \times 10^{-5} \mathrm{~Pa} \cdot \mathrm{s}$ & Fracturing fluid viscosity & $3 \times 10^{-3} \mathrm{~Pa} \cdot \mathrm{s}$ \\
Boltzmann constant & $1.38 \times 10^{-23} \mathrm{~J} / \mathrm{K}$ & Collision diameter of gas & $4.2 \times 10^{-10} \mathrm{~m}$ \\
\hline
\end{tabular}

The geometry of the simulated reservoir is shown in Figure 8. The hydraulic fracture is assumed as a rectangle and it fully penetrates the height of the reservoir. If the gravity effect is neglected, the reservoir is simplified to the $2 \mathrm{D}$ case. 


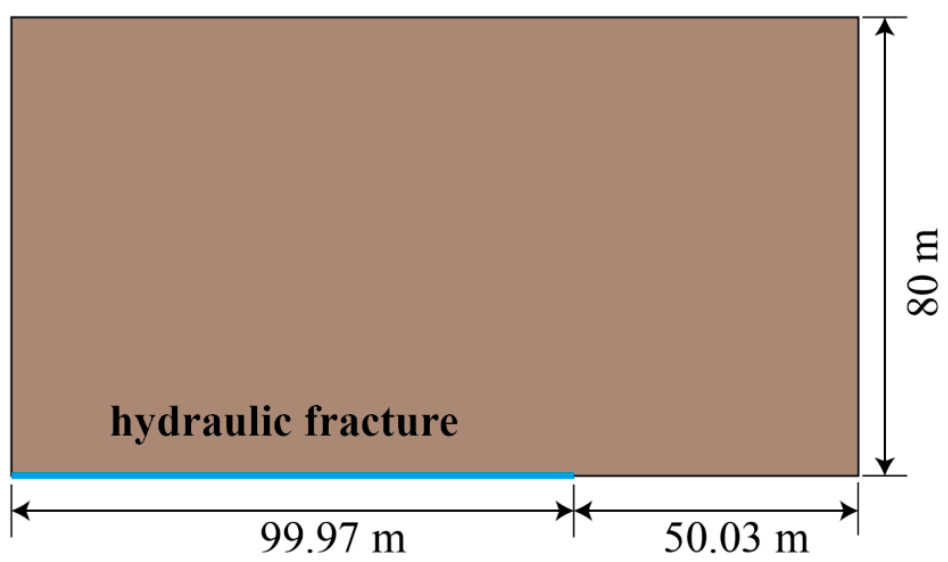

Figure 8. The geometry of the stimulated reservoir.

In the injection process, two boundary conditions are given at the hydraulic fracture:

$$
\begin{aligned}
-\left.\frac{k}{\mu_{w}} \nabla p_{w}\right|_{\Gamma_{F}} & =\frac{Q_{w}}{2 H_{f} L_{f}}, \\
\left.s_{w}\right|_{\Gamma_{F}} & =1,
\end{aligned}
$$

where $Q_{w}$ is the injection rate of the fracturing fluid. $H_{f}$ and $L_{f}$ are, respectively, the height and the length of the hydraulic fracture. $\Gamma_{F}$ stands for the hydraulic fracture.

During the shut-in time, no fluids flow out from the formation. The bottom hole pressure changes as the time goes on. The "no flow" boundary allows no fluids to enter into the formation from the fracture surface. The pressure change in the fracture surface can be simulated when the "no flow" boundary is applied to the fracture surface. The following boundary condition is applied to the hydraulic fracture:

$$
-\left.\frac{k}{\mu_{w}} \nabla p_{w}\right|_{\Gamma_{F}}=0
$$

During the production process, the following boundary condition is applied to the hydraulic fracture:

$$
\left.p\right|_{\Gamma_{F}}=p_{w}
$$

The other outer boundaries are still set as nonflow boundaries, i.e., Equation (21).

Before carrying out the data matching, there are four steps. First, the geometry of the stimulated reservoir is established in Figure 8, and then it should be meshed. Quadrilateral grids are adopted in this paper. Second, the basic parameters listed in Table 4, including the relative permeability functions (Equations (11)-(12)), capillary pressure function (Equation (13)), and the imbibition function (Equation (14)) are inputted into the program. Third, three analysis steps are set in the program-i.e., injecting fluids first, then shutting the well, and finally production-and the conditions are given in Equations (19)-(22). Finally, the timestep is set to $1 \mathrm{~h}$ before starting the solution program.

As can be seen from Figures 9 and 10, the simulation results have a good agreement with the field data. In Figure 9, the sudden drop in field gas rate is also predicted by the simulation results. 


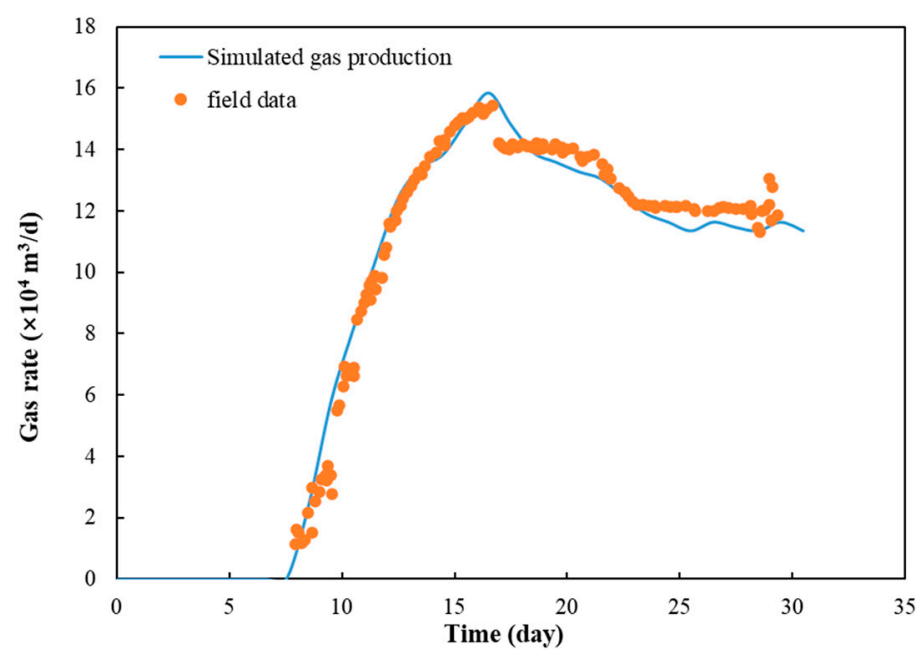

Figure 9. A comparison between the field data and the simulated gas production.

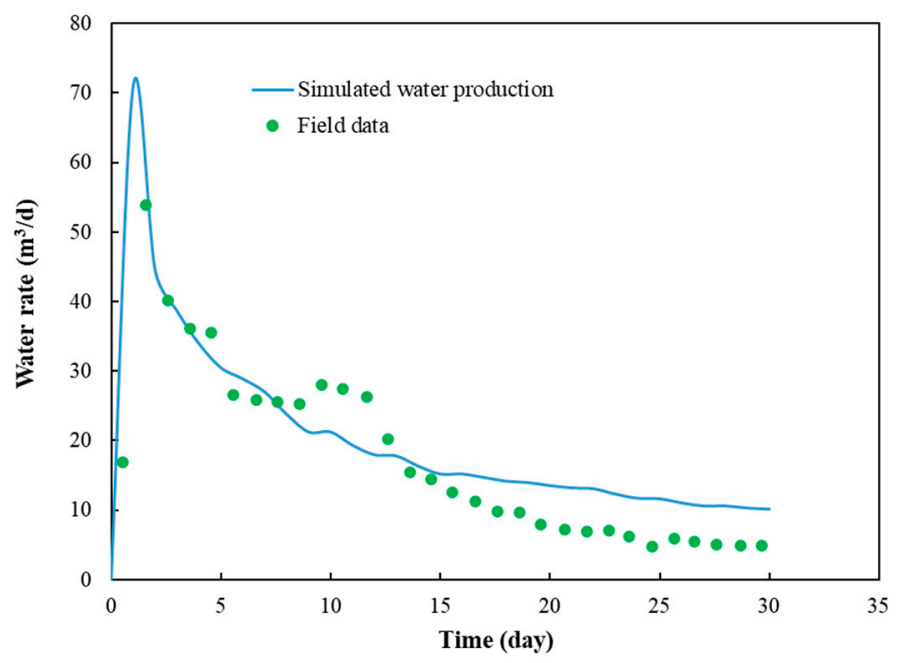

Figure 10. A comparison between the field data and the simulated water production.

\section{Results and Discussion}

In this section, the simulation result was discussed as the effect of imbibition on the production and shut-in time optimization.

\subsection{Imbibition Effect on Gas Production}

Based on the experimental data from Woodford shale samples [17], it indicated that the initial water saturation was irreducible, which meant that the original saturated region was a single gas flow region. After fracturing, the near hydraulic fracture region creates a gas-water flow. The gas-water flow region lowers the gas production [18]. Figure 11 shows the influence of imbibition on gas production. The shut-in time is 1 day in Figures 11-13. It can be seen from Figure 11 that the imbibition effect improves the gas production and shortens the time of obtaining the gas flow. When we consider the influence of imbibition, the accumulated gas production is $2.53 \times 10^{8} \mathrm{~m}^{3}$, which is 12.68 percent higher than that neglecting the influence of imbibition. The scenario without considering the imbibition effect is calculated using the published research of Wei et al. [18]. 


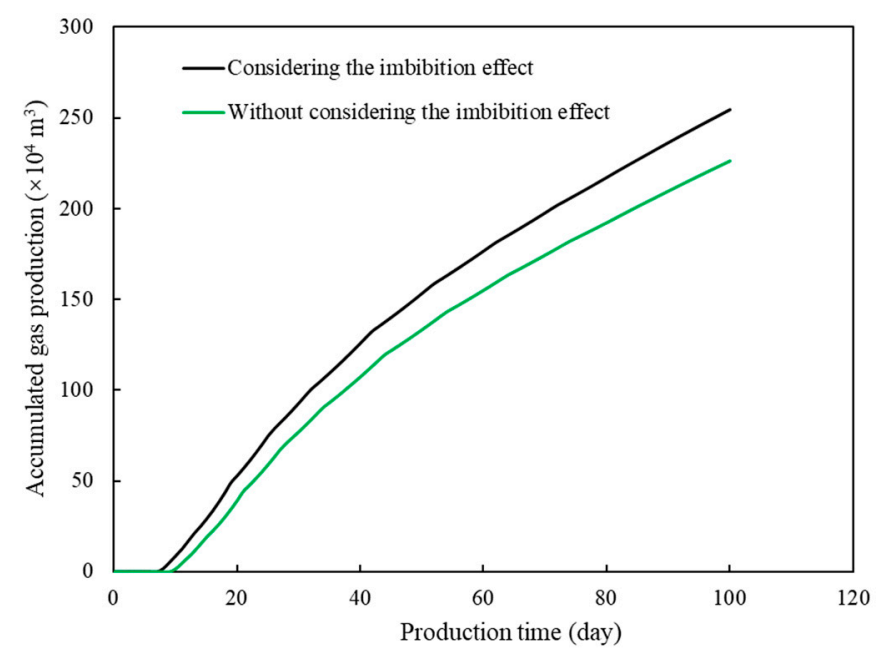

Figure 11. The influence of imbibition on gas production; the shut-in time is 1 day.

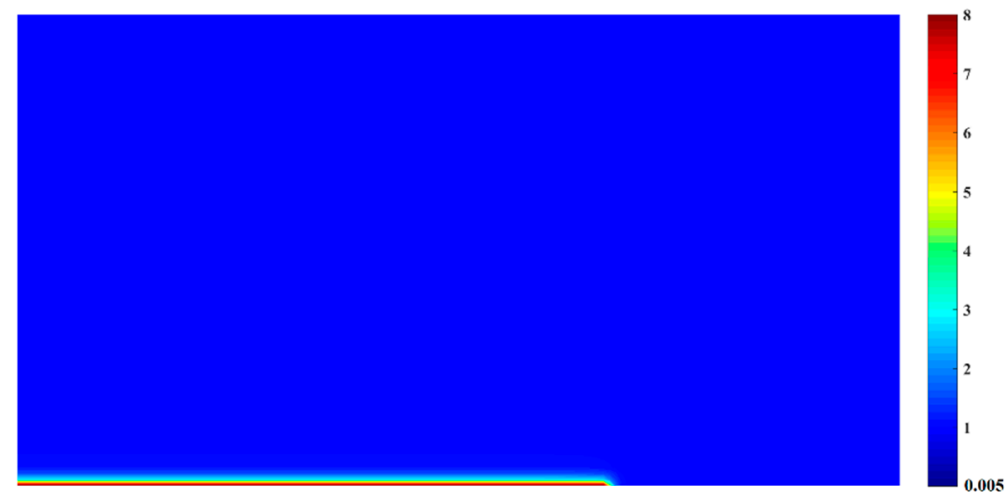

Figure 12. The distribution of dimensionless gas permeability considering the imbibition effect-i.e., $k \cdot k_{r g} / k_{0}$. The shut-in time is 1 day.

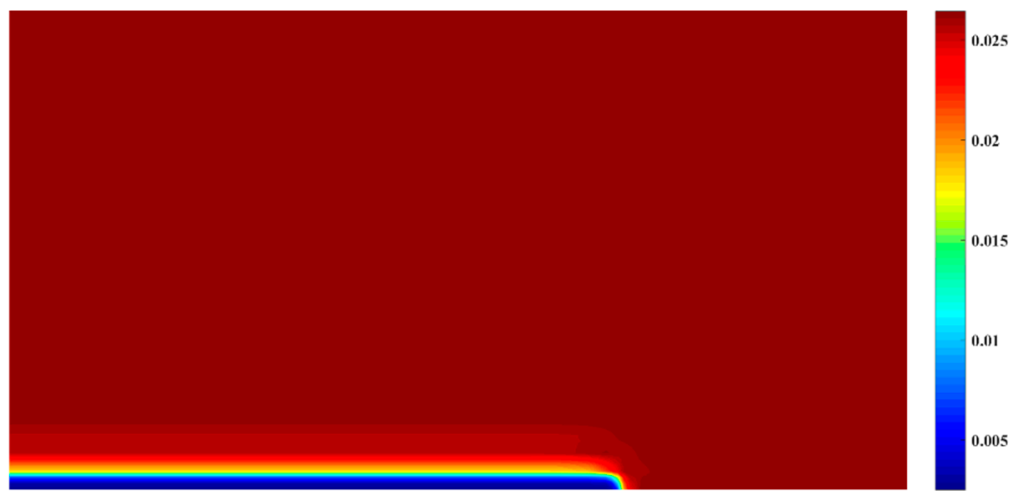

Figure 13. The distribution of dimensionless gas permeability without considering the imbibition effect-i.e., $k \cdot k_{r g} / k_{0}$. The shut-in time is 1 day.

Figure 12 shows the distributions of the dimensionless permeability of shale considering the imbibition of the fracturing fluid-i.e., $k k_{r g} / k_{0}$, where $k_{0}$ is the initial matrix permeability of the dry shale core. Figure 13 shows the distribution of the dimensionless gas permeability of shale-i.e., $k k_{r g} / k_{0}$, where imbibition is neglected. Figure 12 indicates that the dimensionless gas permeability in the vicinity of hydraulic fracture is up to 8 when the imbibition happens. The enhanced gas permeability near hydraulic fractures is the reason for improving the gas production. However, when neglecting the imbibition effect, the dimensionless gas permeability near the hydraulic fracture is as low as 0.0025 . The damaged gas permeability in the vicinity of the hydraulic fractures is responsible 
for the decline in gas production [18]. Comparing the region size of the enhanced gas permeability in Figure 12 and damaged gas permeability in Figure 13, we know that the effective distance of the capillary pressure-driven imbibition is much shorter than the pressure difference-driven water flow.

Figures 14 and 15 show the distributions of pore pressure (water phase pressure) and water saturation after shutting the well for various days. It can be seen from Figure 14 that the longer the shut-in time, the larger the pressurized region is but the lower the BHP (Bottom Hole Pressure) is. Figure 15 points out that if the shut-in time is longer, the imbibed region becomes larger. When the well is only shut in for 1 day, the fracturing fluid is concentrated near the hydraulic fracture, and the water intrudes into the shale matrix $8.4 \mathrm{~m}$ after being shut in for 1 day. For the scenarios shut-in 3 days and shut-in 5 days, the water intrudes into the shale matrix 23.5 and $32 \mathrm{~m}$, respectively. Thus, the flowback rate of the fracturing fluid is fast. After 3 days of shutting well, more fracturing fluid is imbibed into the shale matrix. This could cause more inner gas to be displaced by the fracturing fluid to obtain the initial gas production.

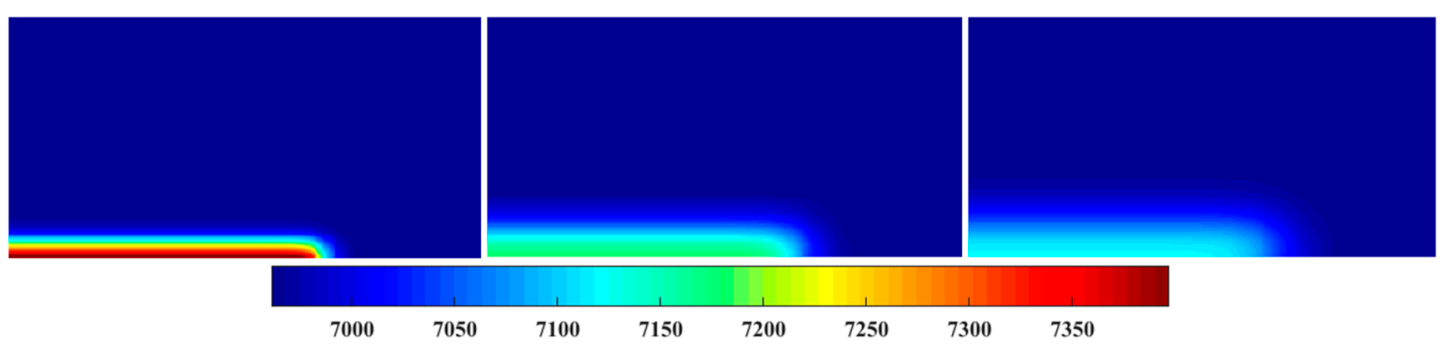

Figure 14. The distributions of the pore pressure of different shut-in time scenarios (from left to right: 1 day, 3 days, 5 days).

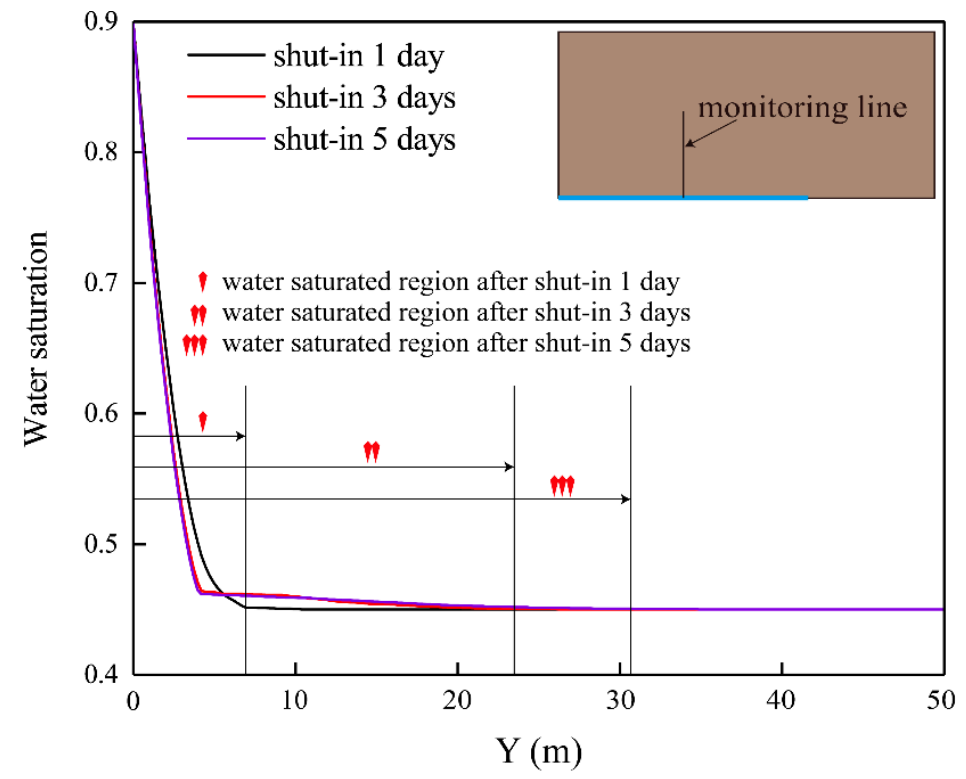

Figure 15. The distributions of water saturation along the monitoring line perpendicular to the fracture.

\subsection{Shut-In Time Optimization}

The fracturing fluid is pumped into the reservoir through hydraulic fractures and then imbibed into the shale matrix. When the well is shut after hydraulic fracturing, two effects of the fracturing fluid exist: (1) the fracturing fluid enters the matrix pores, thus the gas relative permeability declines; (2) the microfractures were clearly observed after the imbibition experiment in shale rocks, which had no observed fractures before the experiment. In addition, the permeability testing indicated that there was a big improvement in permeability after imbibition. In the testing, the permeability of shale after imbibition can be up to 153.57 times higher than the original permeability [17]. 
The gas production and flowback volume in the first 100 days are analyzed in the flowback optimization. The accumulated gas production after 100 days is chosen as the selection index of optimal shut-in time. Five scenarios of shut-in time are analyzed in this section; for more obvious contrast, only three scenarios are shown in Figures 16 and 17. In Figure 16, it is indicated that the accumulated gas production of the shut-in 3 days scenario is the largest, which means that the optimal shut-in time is 3 days. When the well is shut for 1 day, the gas flow is obtained from the reservoir after 7 days flowback of the fracturing fluid. When the well is shut for 3 days and 5 days, the initial gas productions are, respectively, $2.955 \times 10^{6}$ and $2.792 \times 10^{6} \mathrm{~m}^{3}$.

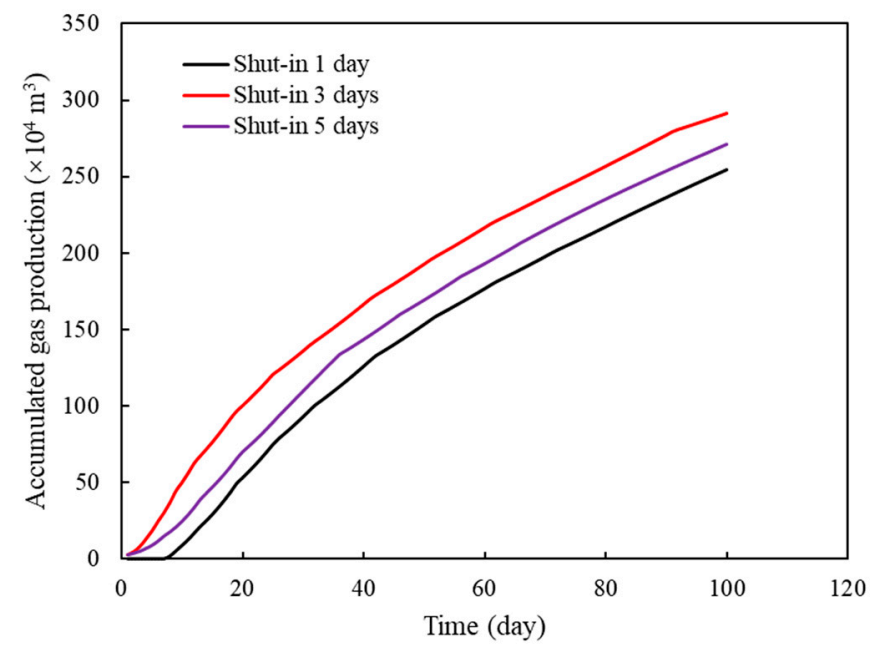

Figure 16. The accumulated gas production of 3 different shut-in time scenarios.

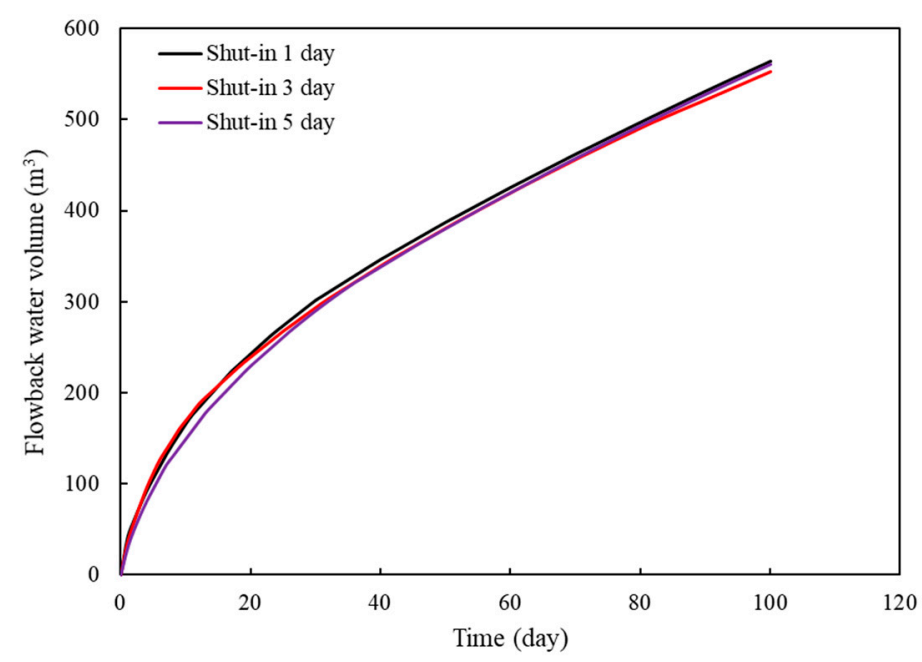

Figure 17. The flowback water volume of 3 different shut-in time scenarios.

It can be seen from Figure 17 that the shut-in time has little influence on the flowback water volume. Therefore, we will focus on the relationship between the shut-in time and gas production.

The shut-in time and corresponding accumulated gas production after 100 days are plotted in Figure 18. Due to the two opposite influences of fracturing fluid on the shale matrix (i.e., with the increase in water saturation, imbibition increases the absolute permeability of the shale matrix; however, the gas relative permeability declines), the accumulated gas production is not monotonically related to the shut-in time. The largest accumulated gas production can be achieved after shutting the well for 3 days. 


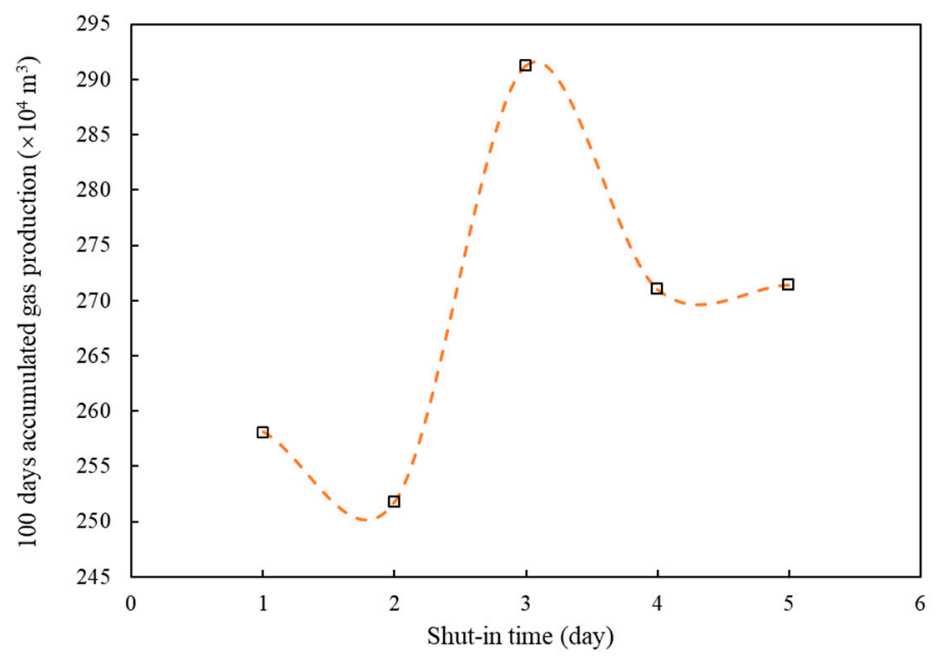

Figure 18. The relation between 100 days accumulated gas production and the shut-in time.

\section{Conclusions}

This paper developed a numerical model coupling the imbibition of fracturing fluid with the gas-water flow model. This model is used to investigate the effect of imbibition on Woodford shale. The experimental and field data of Woodford shale formation were matched by the model to study the effect of imbibition on gas production and shut-in time optimization. The numerical model enables us to efficiently optimize the shut-in time to achieve a high engineering profit. Taking the Woodford Shale as an example, we contrasted the effect of imbibition on gas production and optimized the best shut-in time. The conclusions are the following.

Imbibition is shown to cause a matrix permeability decrease, while the unstable natural fracture permeability increases in the experiment. When the numerical model was developed, the relationship between the imbibed fluid volume and permeability change was considered and matched. Hence, this gas-water coupled imbibition model can be used to simulate the effect of imbibition on permeability, production, and water recovery. For Woodford Shale, the gas phase permeability is 8 times higher than the initial matrix permeability after imbibition, which shortens the time of obtaining the gas flow.

When applying for the experimental and field data of the Woodford shale formation as an example, the simulating result indicates that the model that considers the imbibition effect could provide a more accurate result of gas production. When considering the imbibition effect, the accumulated gas production after 100 days production is 12.68 percent higher than that neglecting the influence of imbibition.

According to the simulation, when the well is shut in during hydraulic fracturing, imbibition affects the permeability and gas production. During the early days, the imbibed fluid makes natural fractures unstable to increase the formation permeability. That increase can bring a higher gas production. Meanwhile, when larger volumes of fluid are imbibed in the formation, the gas production becomes worse because the gas flow in the porous medium is restrained by the imbibed fluid so that the relative gas permeability is low. Therefore, the shut-in time of hydraulic fracturing should be optimized to maximize gas production. Based on the simulation results, the optimal shut-in time of Woodford Shale is 3 days.

The flow back volume is also simulated in the model to explain the reason for the low water recovery after hydraulic fracturing in shale formations.

The contribution of this work is to close the gap between the laboratory and the field. It is helpful to understand the mechanism affecting the flow back and production after hydraulic fracturing in shale formations. 
Author Contributions: Conceptualization, Z.Z.; Methodology, Z.Z. and S.W.; Formal analysis, S.W.; Data Curation, S.W.; Investigation, Z.Z. and S.W.; Resources, R.L.; Validation, R.L. and X.L.; Writing-Original Draft, Z.Z. and S.W.

Funding: This research was funded by National Natural Science Foundation of China (Grant No. 51704306).

Conflicts of Interest: The authors declare no conflicts of interest.

\section{Appendix A Control Equations of Two-Phase Flow}

The fracturing fluid and rock are seen as slightly compressible material:

$$
\begin{gathered}
c_{w}=\frac{\partial \rho_{w}}{\rho_{w} \partial p_{w}}, \\
c_{p}=\frac{\partial \phi}{\phi \partial p_{w}},
\end{gathered}
$$

where $c_{w}$ and $c_{p}$ are the compressibility coefficients of fracturing fluid and rock pores, respectively.

With Equations (A1) and (A2), the time derivative term of Equation (1) can be expressed as:

$$
\frac{\partial\left(\phi \rho_{w} S_{w}\right)}{\partial t}=\rho_{w} \phi c_{t w} S_{w} \frac{\partial p_{w}}{\partial t}+\rho_{w} \phi \frac{\partial S_{w}}{\partial t}
$$

where $c_{t w}=c_{w}+c_{p}$.

The convection term of Equation (1) can be simplified as (Wei et al. 2020):

$$
\nabla \cdot\left(K \rho_{w} \lambda_{r w} \nabla p_{w}\right)=K \rho_{w} \lambda_{r w} \nabla^{2} p_{w}
$$

where $\lambda_{r w}=k_{r w} / \mu_{w} . K$ and $\lambda_{r w}$ are both functions of water saturation, so $\nabla S_{w} \cdot \nabla p_{w}$ appears in the derivation of Equation (A4). However, $\nabla S_{w} \cdot \nabla p_{w}$ is neglected as the quadratic infinitesimal (Wei et al. 2020).

Substituting Equations (A3) and (A4) into Equation (1), the control equation of the fracturing fluid flow is given below:

$$
\phi c_{t w} S_{w} \frac{\partial p_{w}}{\partial t}+\phi \frac{\partial S_{w}}{\partial t}=K \lambda_{r w} \nabla^{2} p_{w}
$$

Similarly, we get the control equation of the shale gas flow:

$$
\phi c_{t g} S_{g} \frac{\partial p_{g}}{\partial t}+\phi \frac{\partial S_{g}}{\partial t}=\kappa \widetilde{k} \lambda_{r g} \nabla^{2} p_{g}
$$

where $c_{t g}=c_{g}+c_{p}, \lambda_{r g}=k_{r g} / \mu_{g}$. From Equation (5), we get:

$$
c_{g}=\frac{\partial \rho_{g}}{\rho_{g} \partial p_{g}}=\left(\frac{M}{Z R T}-\frac{p M}{Z^{2} R T} \frac{\partial Z}{\partial p_{g}}\right) /\left(\frac{Z R T}{p M}\right)=\frac{1}{p_{g}}-\frac{1}{Z} \frac{\partial Z}{\partial p_{g}} .
$$

Substitute Equations (4)-(A6), and neglect the time derivative of capillary pressure, then Equation (A6) can be expressed as:

$$
\phi c_{t g} s_{g} \frac{\partial p_{w}}{\partial t}+\phi \frac{\partial s_{g}}{\partial t}=\widetilde{K k} \lambda_{r g}\left(\nabla^{2} p_{w}+\frac{d p_{c}}{d s_{w}} \nabla^{2} s_{w}\right) .
$$

Adding Equations (A5)-(A8), we get:

$$
\phi\left(c_{t w} s_{w}+c_{t g} s_{g}\right) \frac{\partial p_{w}}{\partial t}=K \lambda_{t} \nabla^{2} p_{w}+\widetilde{K k} \lambda_{r g} \frac{d p_{c}}{d s_{w}} \nabla^{2} s_{w},
$$

where $\lambda_{t}=\widetilde{k} \lambda_{r g}+\lambda_{r w}$. 
Equations (A5) and (A9) constitute the mathematical model of gas-water flow in porous media. Equations (A5) and (A9) can be assembled into the matrix form:

$$
\left[\begin{array}{cc}
\phi\left(c_{t g} s_{g}+c_{t w} s_{w}\right) & 0 \\
\phi c_{t w} s_{w} & \phi
\end{array}\right]\left(\begin{array}{c}
\frac{\partial p_{w}}{\partial t} \\
\frac{\partial s_{w}}{\partial t}
\end{array}\right)+\left[\begin{array}{cc}
-K \lambda_{t} & \widetilde{K} \lambda_{r g} \frac{d p_{c}}{d s_{w}} \\
-K \lambda_{r w} & 0
\end{array}\right]\left(\begin{array}{c}
\nabla^{2} p_{w} \\
\nabla^{2} s_{w}
\end{array}\right)=0
$$

Equation (A10) is discretized using the FEM (Finite element method) and FVM (Finite volume method) methods, thus the discretized form of flow equation in the shale matrix is given in Equation (A12). When discretizing the flow space, we choose a shape function $N$ to discretize the weak governing formulations. Variants that need to be solved can be expressed as:

$$
p_{w}=N p_{n}, \quad s_{w}=N s_{n}
$$

where $N$ is the shape function. $p_{n}$ and $s_{n}$ are, respectively, the nodal water pressure and water saturation.

$$
\left[\begin{array}{cc}
\phi\left(c_{t w} s_{w}+\left(1-s_{w}\right) c_{t g}\right) \mathbf{M} & 0 \\
\phi c_{t w} s_{w} \mathbf{M} & \phi \mathbf{M}
\end{array}\right]\left(\begin{array}{c}
\dot{\boldsymbol{p}}_{w} \\
\dot{\boldsymbol{s}}_{w}
\end{array}\right)+K\left[\begin{array}{cc}
\mathbf{T}\left(\lambda_{w}\right)+\mathbf{T}\left(\lambda_{r g}\right) \widetilde{k} & \mathbf{T}\left(\lambda_{r g}\right) \widetilde{k} \frac{d p_{c}}{d s_{w}} \\
\mathbf{T}\left(\lambda_{r w}\right) & 0
\end{array}\right]\left(\begin{array}{c}
\boldsymbol{p}_{w} \\
\boldsymbol{s}_{w}
\end{array}\right)=0
$$

where $\mathbf{M}$ and $\mathbf{T}$ are, respectively, the mass matrix and the stiffness matrix. $p_{w}$ and $s_{w}$ represent the water phase pressure and the water saturation in the shale matrix. The superscript dot of $p_{w}$ and $s_{w}$ means their time derivative.

$$
\begin{gathered}
\mathbf{M}=\int_{\Omega_{m}} N^{T} N d \Omega, \\
T\left(\lambda_{r g}\right)_{i j}=\lambda_{r g}^{i \rightarrow j}\left(\frac{\partial N_{i}}{\partial x} \frac{\partial N_{j}}{\partial x}+\frac{\partial N_{i}}{\partial y} \frac{\partial N_{j}}{\partial y}\right), \\
T\left(\lambda_{r w}\right)_{i j}=\lambda_{r w}^{i \rightarrow j}\left(\frac{\partial N_{i}}{\partial x} \frac{\partial N_{j}}{\partial x}+\frac{\partial N_{i}}{\partial y} \frac{\partial N_{j}}{\partial y}\right) .
\end{gathered}
$$

\section{References}

1. Almulhim, A.; Alharthy, N.; Tutuncu, A.N.; Kazemi, H. Impact of Imbibition Mechanism on Flowback Behavior: A Numerical Study. Presented at the Abu Dhabi International Petroleum Exhibition and Conference, Abu Dhabi, UAE, 10-13 November 2014.

2. Bertoncello, A.; Wallace, J.; Blyton, C.; Honarpour, M.; Kabir, C.S. Imbibition and Water Blockage in Unconventional Reservoirs: Well Management Implications during Flowback and Early Production. Presented at the SPE/EAGE European Unconventional Resources Conference and Exhibition, Vienna, Austria, 25-27 February 2014.

3. Alkouh, A.B.; Wattenbarger, R.A. New Advances in Shale Reservoir Analysis Using Flowback Data. Presented at the SPE Eastern Regional Meeting, Pittsburgh, PA, USA, 20-22 August 2013.

4. Fakcharoenphol, P.; Torcuk, M.A.; Wallace, J.; Bertoncello, A.; Kazemi, H.; Wu, Y.; Honarpour, M. Managing Shut-in Time to Enhance Gas Flow Rate in Hydraulic Fractured Shale Reservoirs: A Simulation Study. Presented at the SPE Annual Technical Conference and Exhibition, New Orleans, LA, USA, 30 September-2 October 2013.

5. King, G.E. Thirty Years of Gas Shale Fracturing: What Have We Learned? Presented at the SPE Annual Technical Conference and Exhibition, Florence, Italy, 19-22 September 2010.

6. Fan, L.; Thompson, J.W.; Robinson, J.R. Understanding Gas Production Mechanism and Effectiveness of Well Stimulation in the Haynesville Shale through Reservoir Simulation. Presented at the Canadian Unconventional Resources and International Petroleum Conference, Calgary, AB, Canada, 19-21 October 2010.

7. Ghanbari, E.; Abbasi, M.A.; Dehghanpour, H.; Bearinger, D. Flowback Volumetric and Chemical Analysis for Evaluating Load Recovery and Its Impact on Early-Time Production. Presented at the SPE Unconventional Resources Conference, Calgary, AB, Canada, 5-7 November 2013. 
8. Liu, S.; Wang, J.; He, H.; Wang, H. Mechanism on imbibition of fracturing fluid in nanopore. Nanosci. Nanotechnol. Lett. 2018, 10, 87-93. [CrossRef]

9. Roychaudhuri, B.; Tsotsis, T.; Jessen, K. An Experimental Investigation of Spontaneous Imbibition in Gas Shales. Presented at the SPE Annual Technical Conference and Exhibition, Denver, CO, USA, 30 October-2 November 2011.

10. Makhanov, K.; Dehghanpour, H.; Kuru, E. An Experimental Study of Spontaneous Imbibition in Horn River Shales. Presented at the SPE Canadian Unconventional Resources Conference, Calgary, AB, Canada, 30 October-1 November 2012.

11. Makhanov, K.; Dehghanpour, H.; Kuru, E. Measuring Liquid Uptake of Organic Shales: A Workflow to Estimate Water Loss during Shut-in Periods. Presented at the SPE Canadian Unconventional Resources Conference, Calgary, AB, Canada, 5-7 November 2013.

12. Zhou, Z.; Hoffman, T.; Bearinger, D.; Li, X.; Hazim, A. Experimental and Numerical Study on Spontaneous Imbibition of Fracturing Fluids in the Horn River Shale Gas Formation. SPE Drill. Complet. 2016, 31, 168-177. [CrossRef]

13. Wood, D.D.; Schmit, B.E.; Riggins, L.; Johnson, B.J.; Talley, C.A. Cana Woodford stimulation practices-A case history. Presented at North American Unconventional Gas Conference and Exhibition, The Woodlands, TX, USA, 14-16 June 2011.

14. Perry, W.J.; Gautier, D.L.; Dolton, G.L.; Takahashi, K.I.; Varnes, K.L. Arkoma Basin Province (062); Gautier, D.L., Dolton, G.L., Takahashi, K.I., Varnes, K.L., Eds.; U.S. Geological Survey: Denver, CO, USA, 1995.

15. Charoenwongsa, S. Numerical Simulation of the 3-D Hydraulic Fracturing Process, Cleanup and Relevant Physics. Ph.D. Thesis, Colorado School of Mines, Golden, CO, USA, 2011.

16. Lu, R. Investigation of Post Hydraulic Fracturing Well Cleanup Physics in the CANA Woodford Shale. Master's Thesis, Colorado School of Mines, Golden, CO, USA, 2014.

17. Zhou, Z.; Abass, H.; Li, X.P.; Teklu, T. Experimental investigation of the effect of imbibition on shale permeability during hydraulic fracturing. J. Nat. Gas Sci. Eng. 2016, 29, 413-430. [CrossRef]

18. Wei, S.M.; Jin, Y.; Xia, Y.; Lin, B.T. The flowback and production analysis in sub-saturated fractured shale reservoirs. J. Pet. Sci. Eng. 2020, 186, 106694. [CrossRef]

19. Xia, Y.; Jin, Y.; Chen, K.P.; Lin, B.T. Simulation on gas transport in shale: The coupling of free and adsorbed gas. J. Nat. Gas Sci. Eng. 2017, 41, 112-124. [CrossRef]

20. Dranchuk, P.M.; Abou-Kassem, J.H. Calculation of Z Factors for natural gases using equations of state. J. Can. Pet. Technol. 1975, 14, 34-36. [CrossRef]

21. Brooks, R.; Corey, T. Hydraulic Properties of Porous Media; Hydrology Papers; Colorado State University: Fort Collins, CO, USA, 1964; Volume 24, pp. 1-27.

22. Reichenberger, V.; Jakobs, H.; Bastian, P.; Helmig, R. A mixed-dimensional finite volume method for two-phase flow in fractured porous media. Adv. Water Resour. 2006, 29, 1020-1036. [CrossRef]

23. Charoenwongsa, S.; Kazemi, H.; Fakcharoenphol, P.; Miskimins, J. Simulation of Gel Filter-Cake Formation, Gel Cleanup, and Post-Fracture Well Performance in Hydraulically Fractured Gas Wells. SPE Prod. Oper. 2013, 28, 235-245. [CrossRef]

24. Cornell, J.A. Factors that Influence the Value of the Coefficient of Determination in Simple Linear and Nonlinear Regression Models. Phytopathology 1987, 77, 63-70. [CrossRef]

25. Swami, V.; Clarkson, C.R.; Settari, A. Non-Darcy Flow in Shale Nanopores: Do We Have a Final Answer? Presented at the Canadian Unconventional Resources Conference, Calgary, AB, Canada, 30 October-1 November 2012.

26. Cao, P.; Liu, J.; Leong, Y.K. A fully coupled multiscale shale deformation-gas transport model for the evaluation of shale gas extraction. Fuel 2016, 178, 103-117. [CrossRef]

(C) 2020 by the authors. Licensee MDPI, Basel, Switzerland. This article is an open access article distributed under the terms and conditions of the Creative Commons Attribution (CC BY) license (http://creativecommons.org/licenses/by/4.0/). 